\title{
OCCURENCE OF ENTEROCOCCI IN ROOT CANALS AND IN THE IMMEDIATE CLINICAL ENVIRONMENT
}

\author{
Z.A. Che Ab Aziz, S.A. Baharin, \\ D. Spralf, $K$. \\ Gulabivala. Occurence of Enterococci in Root Canals \\ and in the Immediate Clinical Environment Annal Dent \\ Uni:! Malaya 2009; 16: 1-8.
}

\section{ABSTRACT}

This study aimed to detect the presence of enterococci in the root canals of untreated and treated teeth with periapical disease and to compare this to their presence in the saliva and in the immediate surgical environment during root canal treatment. Using an aseptic technique, 33 samples were obtained from 27 untreated and 6 previously treated teeth associated with apical periodontitis. Reduced Transport Fluid (RTF) was used as transport medium. Saliva samples and areas in the surgical environment were also sampled. These were performed prior to chemo-mechanical debrjdement and obturation for every case. The saliva was diluted to 10and was plated on Bile Aesculin. Azide (BEA) agar whereas the rest of the samples were plated on Bile Aesculin (BE) agar. These plates were then incubated aerobically at $37^{\circ} \mathrm{C}$ for 48 hours. All the colony types that blackened the agar were sub-cultured to obtain pure isolates and tested on $6.5 \%$ sodium chloride (NaCI). Growth on this medium was Gram stained for further confirmation of cell morphology. Gram positive cocci isolated from previous positive test were identified as enterococci. Enterococci were recovered from untreated cases only; from 2 teeth (in 2 patients) prior to chemo-mechanical debridement, from 3 teeth (in 3 patients) prior to obturation and I from saliva sample. A total of 5 samples from 5 different patients were positive for enteroco cci. Sampling in the immediate surgical environment revealed a low occurence in the range of $3.0 \%$ (1/33) to $15 \_2 \%(5 / 33)$. In conclusion, the occurence of enterococci in patients and the immediate surgical environment was low number.

Key words: Enterococci; root canals; immediate clinical environment

\section{INTRODUCTION}

Bacterial presence in root canal system has been shown to be the primary cause of pulpal necrosis and subsequently apical periodontitis (1,2). In most cases, apical periodontitis could be successfullyl treated by chemo-mechanical debridement of the root canal system. Failure of root canal treatment is usually caused by intra-radicular bacteria, which might have been inaccessible to instrumentation - (3). Resistant to
Original Article

Z.A. Che Ab Azizl, S.A. Baharin², D. Spratt3, K. Gulabivala ${ }^{3}$

1 Department or Conservative Dentistly'

Faculty of Dentistly', University or Malaya 50603 Kuala Lumplll:

Tel: 03-79674539/4887 . Fax: 03-79674533

2 Departmenlof Operative Dentistl ${ }^{\prime}$

[acuity orDentistl]1 UKM,

Jalan Raja Muda Abdul Aziz,

50300 Kuala Lumpw:

Tel: 03-92897829. Fax: 03-92897798

3 Department of Conservative Dentistly'

Eastman Denlal Institule,

UniversiTY College London,

United Kingdom

Corresponding anthor: Zeli Adura Che Ab Aziz

treatment (4) or might invade the root canal system after treatment through coronal leakage $(5,6)$. In rare instances, extra-radicular infections (7), foreign-body reactions associated with extruded filling materials (8) and cysts (9) could also cause treatment failure. In untreated cases, root canal infection is usually polymicrobial in nature $(3,9)$ with anaerobic microorganisms as the predominant group and approximately equal proportions of Gram-positive and Gram-negative bacteria (10). However, Enterococcusfaecalis has been reported to survive as single species in untreated root canals (11).

The persistent presence of micro-organisms has been reported in spite of mechanical instrumentation (12), use of chemical adjunctives such as antimicrobial irrigants and intra-canal medicaments (13). E. faecalis has been the most common species recovered from root treated teeth with persistent periapical disease $(14,15)$. In addition, the microbial flora associated with root canal treatment failure can 0 ften be characterized as a monoinfection predominated by Gram-positive facultative anaerobes micro-organisms. This predominance is not reflected in the indigenous oral flora. Facultative anaerobic Gram-positive cocci such as a-streptococci and enterococci, PeptostreplOcoccUS species and Proprionibaclerium species have been -detected in the persistent periapical lesions associated with previously root-filled teeth (16). Enterococci are known to have a low susceptibility to intra-canal medication such as calcium hydroxide (17) and also has the ability to invade ill1dcolonize dentinal tubules (18) and therefore could survive chemo-mechanical 
debridement and persistently reinfect obturated (poorly) root canal system. The environment can play a vital role in the nosocomial transmission of microorganisms. One critical factor for transmission of a micro-organism from a person to the environment and then to another person is the ability of that microbe to survive on certain environmental surfaces. Cross contamination occurring during the treatment may be one of the possible routes for enterococci to enter the root canal system, as it is able to survive in hospital fabrics and privacy drapes' (19) and in extreme conditions as at high temperatures (20) while retaining viability and pathogenicity .

At present there are no phenotypic tests able to distinguish unequivocally between all members of the genus Enterococcus from other related genera. Results from Swan's (1954) study concluded that hydrolysis of aesculin on a Bile Aesculin agar (BE), which resulted in the blackening of the medium, is a valid test for enteroco,cci recognition (21). A further selective medium has been formulated for Enterococcus identification which is known as BEA agar. The formula modifies $\mathrm{BE}$ by adding sodium azide and reducing the concentration of bile. The bile (oxygall) inhibits the Gram-positive bacteria other than enterococci, while sodium azide inhibits the Gramnegative bacteria (23). Even so, to identify, the bacteria to the species level, molecular analysis using polymerase chain reaction (PCR) is the best method at present $(45,47)$.

The purrpose of the present study was to detect the presence of enterococci in the untreateB and treated asymptomatic tooth associated with periapical area and in the immediate treatment area prior to chemomechanical debridement and obturation procedures and to compare this to their presence in the saliva and in the immediate surgical environment during root canal treatment.

\section{MATERIALS AND METHODS}

\section{Sampling procedures in patients.}

Patients who had not received any systemic antibiotic therapy in the preceding 3 months were selected. Teeth scheduled for non-surgical root canal treatment or re-treatment which was associated with radiographic evidence of periapical disease was included. However, those teeth that could not be isolated satisfactorily nor had root fillings that could not be rcmoved within 30 minutes were excluded. Selected patient's saliva was collected using sterile swab prior to rubber dam placement. Buccal mucosa and the tooth surfaces were swabbed and transferred to a I ml RTF. The saliva was labeled and taken to the microbiology laboratory for processing within 1-7 hours. The inoculated RTF was vortexed for 30 seconds and then plated onto a selective medium (BE) (Bile Aesculin Agar Difco, Becton Dickinson, USA) for enterococci using sterile plastic spreaders. The samples were then incubated aerobically, with $5 \%$ carbon dioxide in air for 48 hours at $37^{\circ} \mathrm{C}$. These colonies were then subcultured on to $6.5 \%$ sodium chloride $(\mathrm{NaCl})$, agar. The colonies were counted as enterococci if they blackened the $\mathrm{BE}$ as well as grew on the $6.5 \% \mathrm{NaCl}$ agar.. Additionally Gram's stain was performed for every positive result. for final confirmation.

\section{Sampling in root canals}

\section{a) Prior to chemo-mechanical debridement}

\section{Untreated teeth}

The selected teeth were anaesthesized and isolated with rubber dam. The tooth margin was sealed with a thin layer of Oraseal'm (Cauk, Opident, North Yorkshire, UK) to prevent any saliva leakage. The tooth surfaces, rubber dam and clamp were swabbed with $30 \%$ (v/v) hydrogen peroxide (Sigma Chemical Limited, St. Louis, USA) for 1 minute and subsequently with $] 0 \% \quad$ IV/V) " povidone-iodine (Betadine, Seton Healthcare Group pIc, Oldham, England) for a further I minute. The iodine solution was inactivated with $5 \%(\mathrm{v} / \mathrm{v})$ sodium thiosulphate solution (BDH, Poole, England). The access cavity was carefully prepared by using sterile burs. Decontamination - procedures were repeated after the access cavity was made, and care was taken so that no disinfectant entered the pulp chamber. A sterile instrument was introduced into the root canals to the apical foramen (determined with apex locator) and the walls were filed gently with a sterile ISO size $] 0$ or 15 Flexo-file (Kerr' UK Limited, Peterborough, UK) to release debris. If the root canal was found to be dry, phosphate buffered saline (PBS) solution (Oxoid, Basingstoke, UK) was syringed into the canal. PBS solution was not introduced into a wet canal. Three sterile white paper points (Roeko, Langenau,. Germany) were used to sample the root canal by leaving each paper point in the root canal for 30 seconds. The wet portions of the paper points were then cut and placed into I ml RTF vials.

\section{Treated teeth}

For re-treatment cases, In addition to decontamination and access protocol as above, the gutta-percha was removed with sterile 15 or 20 Hedstrom files (Kerr UK Limited, Peterborough, UK) and Gates Glidden drills (Caludius, ASH, England). Chloroform was only used if necessary and limited to the removal of gutta-percha at the coronal area. Working length of the root canal was checked with an apex locator. At this stage no irrigant such as sodium hypochlorite was used. PBS was introduced into the canals and the contents sampled as untreated teeth.

\section{b) Prior to obturation}

Prior to obturation, further samples were taken from root canal and the corresponding. saliva. The teeth 
were isolated and surface decontaminated as previously described. After removal of temporary filling material i.e Intermediate Restorative Material (IRM) and cottonwool pledget with sterile burs or ultrasonic scalers (Claudius, ASH, England), the decontamination procedures are repeated. Intra canal medication (calcium hydroxide) was carefully irrigated with PBS and canal patency was checked with small file and apex locator. Three sterile paper points were used to sample the canal as in the pre-operative stage. All root canal samples were labeled and taken to the microbiology laboratory and processed as before.

\section{Immediate surgical environment sampling}

On each selected cases, the surgical environment (21 sites as below) were swabbed with sterile swab. Samples were taken at each appointment (ie prior to chemo-mechanical debridement and prior to obturation) from the following locations using sterile swab. Each of the swabs was placed into $1 \mathrm{ml}$ of RTF and labeled. At the end, similar inoculation and incubation procedures as in teeth sampling were conducted. The locations were:

- Acetate sheets with radiographic films mounted

- Arm rests of dental chairs

- Burs

- Dental unit light handles

- Drawer handles of operator-(OP) and dental nurse (DN) side

- Foot rest of dental chair

- Gloves of OP and DN

- Hand pieces

- Microscope if used

- OP clinical coat

- Patient's folder

- Radiograph viewer box switch

- Triple syringe of OP and DN

- Water delivered from the triplex syringe of OP and DN

- Water taps of OP and DN síde

- X-ray machine üsed

\section{RESULTS}

\section{Presence of entcrococci in oral cavity and root} canals

Thirty patients were recruited. In total, 33 sets of root canals and saliva samples were obtained for culturing. Twenty-seven sets of root canal samples were taken from untreated teeth, while 6 sets of samples were obtained from re-treatment cases. Chloroform was used in all re-treatment cases.

Enterococci were only detected in two $(6 \%)$ saliva samples during both root canal treatment procedures i.e. prior to chemo-mechanical debridement and obturation. The samples were not obtained from the same patient and no enterococci were detected in the root canals of these two patients. The presence of enterococci detected in root canals was very low. Only 3 out of 33 teeth $(9 \%)$ had enterococci detected in their root canals prior to chemo-mechanical debridement and same percentage prior to obturation. Nevertheless, all the positive samples came from different root canals of different patients. (Table I)

\section{Peripheral sampling}

Overall the presence of enterococci prior to ehemomechanical debridement and obturation were very low. The highest site of where the enterococci detected is at the foot-rest area. The numbers of the positive sampling is shown in figure $\mathrm{I}$.

\section{DISCUSSION}

After imposing strict selection criteria, teeth requiring primary root canal treatment or re-treatment were sampled from the patients. This procedure restricted the sample size because the untreated cases required the pulp chamber to be intact, as judged by the radiograph; and in the re-treatment cases, isolation after removal of the existing restoration was a problem as certain samples required a built-up prior to rubber dam placement. M9reover, chloroform was used occasionally to facilitate complete removal of the previous root filling, and it has been shown to possess an antibacterial effect on E. Iaecalis (46). Some samples were also lost du to technical error in sampling and in need of long-term calcium hydroxide placement.

Previous studies, employing root canal sampling have been used anaerobic conditions in order to maintain the viability of strict ananerobic microorganisms. However, since enterococci are facultative anaerobic bacteria which can stay viable in the presence of oxygen, anaerobic conditions were unnecessary. All the samples were taken within 7 hours from the sampling as pilot study conducted showed processing earlier than 7 hours (i.e immediately, I and 3 hours) did not show any great differences in the viability of E.Iaecalis. 1--lencethe necessity to process these samples quickly was not required. Potential bias due to transport medium was minimized by storing the samples in RTF, Sampling was carried out with the help of paper points. A numbq of published studies have advocated the use of paper points for their sampling $(3,38)$. Paper points are able to absorb more fluid and by assumption adsorb more. Hancock nd associates (200 I) compared the efficacy of paper points versus files for sampling, they recovered $61 \%$ bacteria when sampling with the use of paper points and $51.9 \%$ when using files. Whilst paper points are useful for adsorbing surface and planktonic bacteria, those within dentinal tubules would be missed (13).

The oral carriage of enterococci in healthy individuals ranges from $4-75 \%(24,25)$. The broad range emphasizes the problems involved in comparing 
Table 1. Distribution of samples taken from the oral cavity, immediate surgical environment

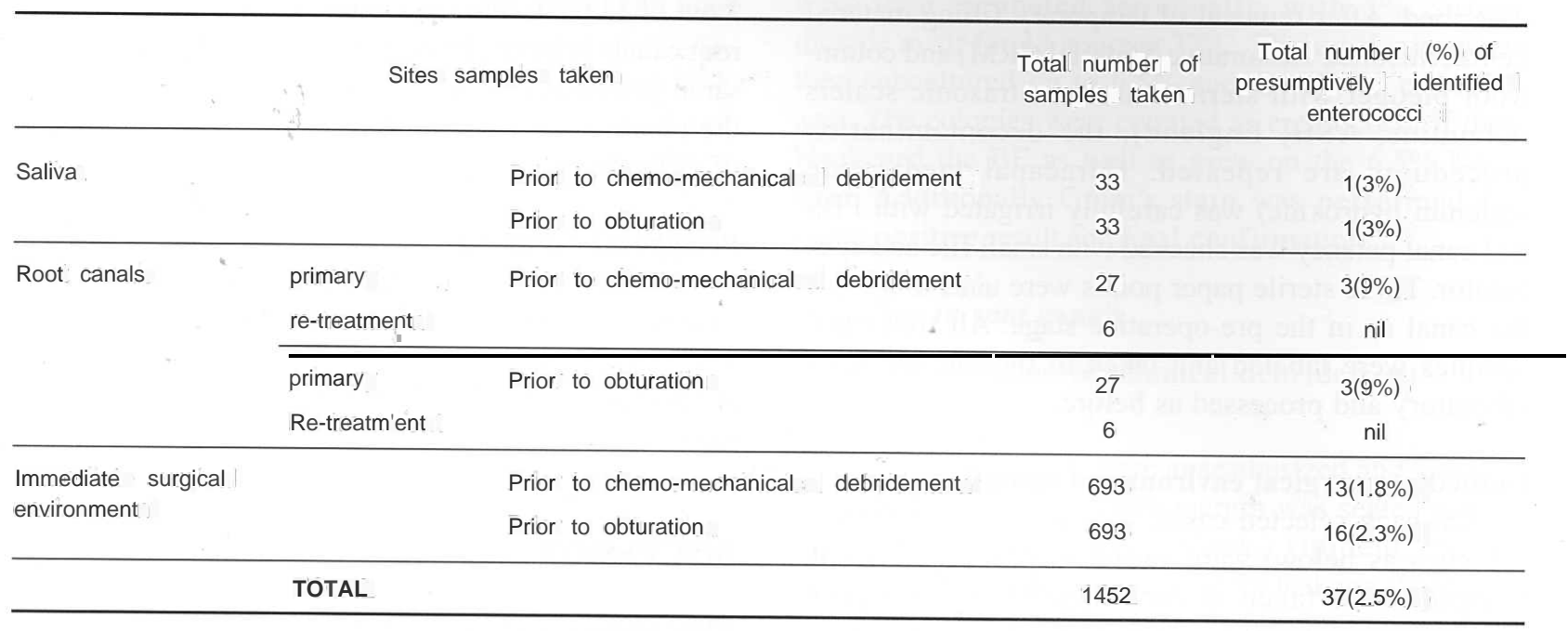

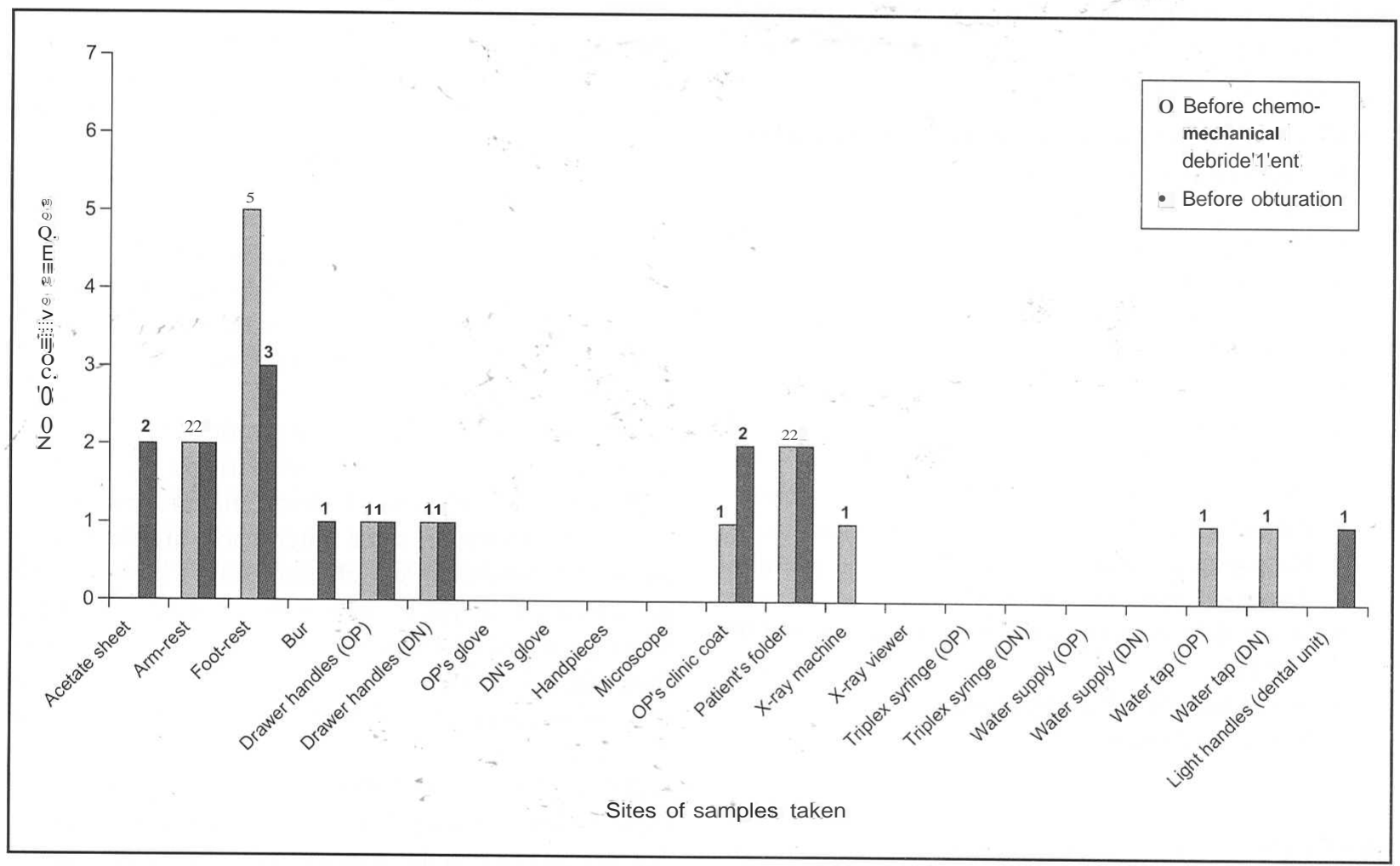

Figure 1: Number of positive samples taken prior to chemo-mechanical debridement and obturation of tooth and from immediate surgical area ( $n=33$ cases) NB: chemo-mechanical debridement and obturation were temporally separate treatment episodes

results, which stem from different criteria used in patient selection, lack of information regarding the sübjects and a wide range of techniques used for sampling, isolation and identification of the enterococci used (26). Studies have reported a lower prevalence of enterococci when more than one test medium was used. Bahn and associates (1960) and Engstrom (1964) used $6.5 \% \mathrm{NaGCl}$ as an additional test for presumptive identification : of enterococci. Meanwhile $30-75 \%$ of enterococci have been recovered when only a single type test medium, usually when the samples were inoculated in a broth form of media (26). This also may explain of the low presence $(6.0 \%)$ of enterococci in saliva. The result : was closer to the percentage recovered in naval recruits, in a study conducted by Bahn and associates (1960) which showed a prevalence of $3.7 \%$. Ifusing only BEA to characterize the bacteria, rather than using additional test ie $6.5 \% \mathrm{NaCI}, 96 \%$ of saliva cultured showed blackening of the media presumptive enterococci identification. 
Previous work has shown that enterococci were cultured from $3 \%-12 \%$ necrotic pulps $(25,27)$ whereas $16 \%-70 \%$ were cultured/detected in root filled teeth $(15,28)$. The limited number of untreated root canals sampled in this study (25) yielded $9.0 \%$ of enterococci, which was within the range of published studies. However, it is difficult to make a comparison for retreatment cases as q ly 6 re-treated teeth were sampled and they revealed no enterococci. This could be explained by the fact that the gutta-percha remnants in the canal blocked out sampling fluid from areas where bacteria were present, thus compromising the validity of the sample. A study by Spangberg \& Engstrom (1968) on the antibacterial properties of chloroform showed that enterococci were more sensitive than staphylococci (22) however in this study the chloroform was limited to the use only at the coronal area. If it required the use of high volume of chloroform or the GP at the apical area could not be removed using Hedstroem file, the tooth won't be included.

Inability to sample more teeth with failed root canal treatment were due to difficulty in achieving isolation prior to removal of previous restorations. Failure to isolate the tooth prior to root filling removal may cause salivary contamination and therefore jeopardize the validity of result obtained. Even though the use of chloroform had been limited to coronal and middle third (if necessary) of the canal, no growth was detected in re-treatment cases. Molander and associates (2002) sampled 100 root-filled teeth and had to use chloroform in 21 cases. Bacterial growth was less frequently observed when cultured compared to the cases where the gutta-percha were removed without the assistance of chloroform (14). This has been supported by a study where chloroform demonstrated to inhibit growth of E. IaecaLis by more than $85 \%$ growth. The tested bacteria however, were directly exposed to the medicament in the test tubes (22).

Mechanical instrumentation alone or In combination with an antimicrobial irrigant, has been shown to be insufficient to completely eliminate intracanal micro-organisms $(29,30)$. Thus, teeth with apical periodontitis also need to be treated with an inter-appointment dressing to remove or further reduce in number any remaining intracanal micro-organisms (31). In spite of the chemo-mechanical .. and intracanal dressing placement, enterococcal nevertheless have been detected prior to obturation although with a low prevalence $(9.0 \%)$. The presence of cultivable enterococci can be due to resistance to the irrigants used, high $\mathrm{pH}$ of calcium hydroxide or contamination from the oral cavity or the surrounding environment. None of the cases of when enterococci were detected prior to chemo-mechanical debridement procedure were re-detected prior to obturation. Enterococci are a common flora of intestinal tract but not of oral cavity (32). Therefore transient cross infection can occur from. faecal-hand-oral or from hand-environment-oral routes (33).

Sodium hypochlorite $2.5 \%-3 \%$ (occasionally with $10 \%$ iodine and $0.2 \%$ chlorhexidine) was IIsed as irrigant during chemo-mechanical debridement procedures together with calcium hydroxide as intracanal dressing. All the irrigants used are known to have antimicrobial properties however; they have differing efficacies with respect to different microbiai species. Although sodium hypochlorite ( $\mathrm{NaOCl}$ ) has been shown to totally eradicate E. IaecaLis either as a planktonic form or as biofilm. (34). It might also be advisable to use chlorhexidine and iodine for irrigation as several in vitro studies have reported ability of these irrigants to eradicate $\boldsymbol{t}$. Iaecalis $(34,35,47)$. These results !1Owever may be confounded by the variation in root canal anatomy and polymicrobial root canal flora.

In the present study, because of its effective antimicrobial activity, $\mathrm{Ca}(\mathrm{OH}) 2$ is used as a routine endodontic regime for interappointment medicament. However, E. faecaLis has been reported to be ineffectively killed using $\mathrm{Ca}(\mathrm{OHh}$ in root canals (17, 36). In fact, Molander and associates (1998) suggested that the use of an intracanal dressing directed specifically toward the anaerobic segment of the microbial brought about a suitable environment for the enterococcal growth (37). Love (2001) has conducted a study to identify a possible mechanis) 11 that would explain how E. Iaecalis could survive and grow within dentinal tubules and reinfect an obturated root canal (38). The ability of E. IaecaLis to completely invade denti nal tubules has been reported (13, 17, 40). Therefore, it $\mathrm{i} \sim$ probable that cells within dentinal tubules could survive the chemo-mechanical instrumentation and intracanal medication. It has been demonstrated thilt E. Iaecalis is able to invade dentine at a lesser degree in the presence of serum, but the binding to immobilized collagen in the tubule's is enhanced. Evans and associates (2002) have showed that E. Iaecalis is able to survive the high $\mathrm{pH}$ (11.1) of $\mathrm{Ca}(\mathrm{OHh}$ due to the presence of proton pump contained in the bacteria cell wall. This pump drives protons into the cell to acidify the cytoplasm. Inhibition of this pump with proton pump inhibitor, carbonyl cyanide m-chlorophenylhydrazone (CCCP) resulted in a dramatic reduction of E. IaecaLis cell viability. This effect was more pronounced after 60 minutes of $\mathrm{Ca}(\mathrm{OH}) 2$ exposure (40).

E. IaecaLis is part of normal oral flora and gastrointestinal tract. It has been reported that these bacteria make up no more than I\% of the intestinal micro flora of an adult (32). Its presence in the root canal prior to obturation is likely to be due to contamination for example from poor temporary restoration which may cause leakage in between appointments. Even though only small percentage of enterococci was found in the saliva $(6.0 \%)$, it may be one of the possible source of these bacteria. 
A high presence of enterococci was mainly detected on the foot rest areas of dental chairs (0.43\%$0.72 \%$ ) compared to other places swabbed. These bacteria may have originated from dirt presence on the shoes of patients. The dirt may be contaminated with enterococci from animal faeces (41). A low presence of enterococci was detected in several sites of the treatment areas, which may be associated with crosscontamination via hands for example drawer handles. A study by Cromptons el al. (1999) showed that when gloved hands were irioculated with Streptococclls sanguis, the bacteria could be transferred from the gloves to the dental records and remain viable for long periods of time (up to $\overline{72}$ hours). Contamination of the drawer handles in the steri lizing bay area may occur via this route. Entcrococci were also detected on the handcuff areas (I case only) of the clinical coat worn by the operators (42). Prolonged survival of enterococci on the clinical coat (fabric type $100 \%$ cotton) has been demonstrated by Neely \& Maley (19). In'order to limit the potential cross-infection occurring, it may prudent to change clinical coat. Entcrococci have also been sampled from the bur, which is used 10 remove temporary restoration. The bur was sterilized by vertical autoclave displacement at $134^{\circ} \mathrm{C}$ for 3 minutes. It may be contaminated during its placement on the hand-piece or the other unlikely possibility is that the bacteria survive the sterilizing procedure. Recent reports have highlighted the tolerance of enterococci to heat. Freeman and colleagues (1994) and Kearns' and associates (1995) reported enterococci were able to resist temperature of $71 D C$ when exposed for 10 minutes, and $81^{\circ} \mathrm{C}$ when exposed for 3 minutes $(20,43)$. Bradley and Fraise (1996) have reported the similar finding of enterococcal heat tolerance. Additionally they have also reported tolerance to a range of antimicrobials i.e $70 \%$ alcohol, $2 \%$ glutaraldehyde or $>1000 \mathrm{ppm}$ of available chlorine releasing agent (44). No enterococci were detected on hand-pieces and water supply. Cross-contamination potential with dental equiptment (especially lumen containing) is possible if vertical displacement autoclave used. However the handpieces arc sterilized by vacuum autoclave displacement $\left(135^{\circ} \mathrm{C}\right)$ to ensure complete sterilization of the internal lumen.

In conclusion, enterococci have been isolated in a small number of teeth. with infected root canal system and in a higher number of failed root canal treatments (28). E. faecalis has also been reported by Fabricius and associates (1982a) to be able to survive as a monoinfection in the root canal and only produce mild inflammation without the presence of other bacteria (II).

from the previous clinical and laboratory studies, it has been shown that enterococci were very difficult to eradicate with routine clinical root canal therapy by using irrigating solutions and intracanal medications $(15,25,31,41)$. Dentine has been reported to have a buffering effect on the medicament used and therefore reduced the expected $\mathrm{pH}$ (45). Ability to attach to collagen of dentinal tubules and re-grow (39) may again partly explain the isolation of enterococci : from persistent apical periodontitis. It is possible that the presence of enterococci, prior to obturation was a result of contamination during the initial treatment. This emphasizes the need to maintain aseptic techniques with adequate placement of inter-appointment temr.0rary dressings. Considering the enterococci were also recovered from the wide range of surrounding environmental areas throughout the period of the study, the possibility exists that cross-contamimition can occur.

\section{REFERENCES}

I. Kakehashi S, Stanley HR, Fitzgerald RJ. The effects of surgical exposures of dental pulps in germ-free and conventional laboratory rats. Oral Surg, Oral Med, Oral Path 1965, 20: 340-9.

2. Moller AJR, Fabricius L, Dahlen G, Ohman AE, Heyden- G. Influence of periapical tissues of indigenous oral bacteria and necrotic pulp tissue in monkeys. Scandinavia J of Den Res 1981, 89: 475-84.

3. Sundqvist G, Johannson E, Sjogren U. Prevalence of black-pigmented Bacteroides species in root canal infection. J of Endod 1989, 15: 13-9.

4. Nair PNR, Sjogren U, Krey G, Kahnberg KE, Sundqvist G. Intraradicular bactcria and fungi in root-filled, asymptomatic human teeth with therapy-resistant periapical lesions: A long term light and electron microscopic follow-up study. J of Endod 1990a, 16: 580-88.

5. Safavi KE, Dowden WE, Langeland K. Influence of delayed coronal pcrmanent restoration on endodontic prognosis. Endod and Dent Traumatol 1987,3: 187-91

6. Saunders WP, Saunders EM. Coronal leakage as a cause of failure in root canal therapy: a review. Endod and Dent Traumatol 1994, 12: 151-4.

7. Nair PNR, Sjogren U, K rey G, Sundqvist G Therapy resistant foreign body giant cell granuloma at the periapex of a root-filled human tooth. J of Endodo 1990, 16: 589-95.

8. Nair PNR, Sjogren U, Schumacher E, Sundqvist G Radicular cys affecting a root-filled human tooth: along term treatment follow-up. Int Endod J 1993 , 26: $225-33$. 
9. Dahlen G, Moller AJR. Microbiology of endodontic infections. [n: Contemporary Oral Microbiology and Immunology (edited by Slots J, Taubman MA) 1992, pg 444-75. Mosby.

10. Sundqvist G. Ecology of root canal flora. J of Endod 1992, 18: 427-30.

II. Fabricius L, Dahlen G, Ohman AE, Moller AJR. Predominant indigenous oral bacteria isolated from infected root ca"nals after varied time of closure. Scan J of Dent Res 1982, 90: 134-44.

12. Bystrom. A, Sundqvist G. Bacteriology evaluation of the efficacy of mechanical root canal instrumentation in endodontic therapy. Scan $\mathbf{J}$ of Dent Res 1981,89: 321-8.

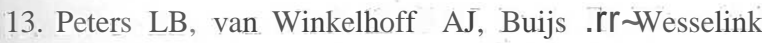
PRo Effects of instrumentation, irrigations and dressing with calcium hydroxide on infection in pulp less teeth with periapical bone lesions. Int Endod J 2002, 35: 13-21.

14. Molander A, Reit C, Dahlen G, Kvist T. Microbiological status of root-filled teeth with periapical pcriodontitis. Int Endod J 2002, 31: 17.

15. Hancock [[1 HH, Sidgurdsson A, Trope M, Moiseiwitsch i. Bacteria isolated after unsüccessful endodontic treatment in a North American population. Oral Surg Oral Med Oral Pathol 2002, 91: $579-86$.

16. Noda M, Komatsu H, Inoue S, Sano H. Antibiotic susceptibility of bacteria detected from the root canal exudates of persistent apical periodontitis. J of Endod 2000, 26: 221-4.

17. Safavi KE, Spanngverg LSW, Langeland K. Root canal dentinal tubules disinfection. $\mathrm{J}$ of Endod 1990, 16: 207-10.

18.0rstavik 0, Haapasalo M. Disinfection of endodontic irrigants and dressings of experimentally infected dentinal tubules. Endod and Dent Traumatàl 1990, 6: 142-49 .

19. Neely AN and Maley MP. Survival of Enterococci and Staphylococci on Hospital Fabrics and Plastic. J Clin Microbiol 2000, 38: 724-6.

20. Kearns AM, Freeman R, Lightfoot NF. Nonsocomial enterococci: resistance to heat and sodium hypochlorite. J of Hosp Infection 1995,30: 193-9.
21. Swan A. The use of a bile-aesculin medium and of Maxted's technique of Lancefield grouping in the identification of enterococci (Group 0 Streptococci), J of Clin Pathol 1954, 7: 160-3.

22. Spangberg L, Engstrom B. Studies on root canal medicaments. IV Antimicrobial effect of root canal medicaments. Odontologisk Revy 1968, 19(2): 187-95.

23. Facklam RR. Comparison of several laboratory media for presumptive identification of enterococci and group D streptococci. Applied Microb 1973, 26: $138-45$.

24. Balm AN, Shklair IL, Mazarella M, Calandra Jc. Incidencc of oral group 0 streptococci. [Abstract] J of Dent Res 1960, 39: 686-687.

25. Engstrom B. The signifance of enterococci in root canal treatment. Odont Revy 1964, 15: 87-1.06.

26. Gold OG, Jordan HV, van Houte 1. The prevalence of enterococci in the human mouth and their pathogenicity in animal models. Archs Oral Bioi 1975.20: 473\}.

27. Siqueira Jr JF, Aetiology of root canal treatment failure: why well treated teeth can fail. Int Endod J 2001，34: 1-10.

28. Molander A, Reit C, Dahlen G, Krist T. Microbial examination of root filled teeth with apical periodontitis [Abstract]. Int Endod J 1994,24: 104.

29. Bystrom A, Stlndqvist G. Bacteriologic evaluation of the efficacy of mechanical root canal instrumentation in endodontic therapy. Scan' J of Dent Res 1981, 89: 321-8.

30. Bystrom A, Sundqvist G. bacterilogic evaluation of the effect of 0.5 percent sodium hypochlorite in endodontic therapy. Oral Surg 1983,55: 307-12.

31. Bystrom A, Sundqvist G. The antibacterial .. action of sodium hypochlorite and EDTA in 60 cases of endodontic therapy. Int $\sim \operatorname{ndod} \mathrm{J} 1985,18: 35-40$.

32. Sghir A, Gramet G, Suau A, Rochet V, Pochart P, Dore 1. Quantification of bacterial groups within human fecal flora by oligonucleotide probe hybridization. Appl Environ of Microb 2000, 66: 2263-6.

33. Brown LM. Helicobacter pylori: Epidemiology and Routes of Transmission. Epidemio Rev 2000, 22(2): 283-97. 
34. Spratt DA, Prattern J, Wilson M, Gulabivala K. An in vitro evaluation of the antimicrobial efficacy of irrigants on biofilms of root canal isolates. Int Endod J 2001, 34: 300-7.

35. Gomes BP, Ferraz CC, Vianna ME, Berber VB, Teixera FB, Souza-Filho FJ. In vitro antimicrobial activity of several concentrations of sodium hypochlorite 'and chlorhexidine gluconate in the elimination of Enterococcus faecalis. Int Endod $\mathrm{J}$ 200 I, 34: 424-8.

36. Stevens RH, Grossman L1. Evaluation of the antimicrobial potential of calcium hydroxide as an intracanal medicament. J of Endod 1983, 9: 37274.

37. Molander - A, Reit C, Dahlen G, Kvist T. Microbiological status of root-filled teeth with apical periodontitis 1998, 31: 1-7.

38. Love RM. Enterococcus faecalis -a mechanism for its role in endodontic failure. Int Endod J 2001, 34: $399-405$

39. Vahdaty A, Pitt Ford TR, Wilson RF. Efficacy of chlorhexidine in disinfecting dentinal tubules in vitro. Endod and Dent "|raumatol 1993, 9: 243-8.

40. Evans M, Davies JK, Sundqvist G, Figdor D. Mechanisms involved in the resistance of Enterococcus faecalis to calcium hydroxide. Tnt J Endod 2002, 35: 221-8.
41. Devriese LA, Laurier L, De Herdt, Haesebrouck F. Enterococcal and streptococcal species isolated from faeces of calves, young cattle and dairy cows. Journal of Applied Bacteriology 1992, 72: 29-31.

42. Crompton N, Griffiths 8M, Wilson M, Mulanny P. The transfer of bacteria to, and survival on, dental records. Microbios 1999,99: 181-7.

43. Freemap R, Kearns AM, Lightfoot NF. Heat resistance of nosocomial enterococci. Lancet 1994, 344: $64-65$.

44. Bradley CR, Fraise AP. Heat and chemical resistance of enterococci. J of Hospt Tnfec 1996, 34: 191-196.

45. Haapasalo H, Siren H, Waltimo T, Orstavik D, Haapasalo M. Inactivation of local root canal medicaments by dentine: an in vitro study. Int Endod J 2000, 33: 126-131.

46. Edgar S, Gordon MJ, Baumgartner C. The antibacterial effect of chloroform on Enterococcus faecalis after gutta-percha removal.. J of Endod 2006,32(12): 1185-1187.

47. C. Stuart, S. Schwartz, T. Beeson, C. Owatz. Enterococcus faecalis: Its Role in Root Canal Treatment Failure and Current Concepts ill Retreatment. $J$ of Endod 2006, 32(2): 93-98. 